\title{
Rwanda 1994: A Study of Medical Support in Military Humanitarian Operations
}

\author{
Lt Col A Hawley \\ OBE, MB, ChB, DMCC, RAMC \\ Chief Instructor
}

Defence Medical Services Training Centre, Keogh Barracks, Ash Vale, Aldershot, Hampshire GU12 5RQ.

SUMMARY: The deployment of British Contingent (BRITCON) to United Nations Force in Rwanda (UNAMIR) ow

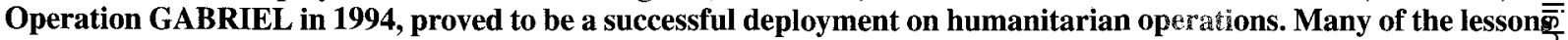
have been successfully incorporated into training, equipment and organisational structires since the deployment Others require further work to develop and assimilate. The essential issue concerning principles of humanitariaa relief doctrine, mission definition, understanding the Disaster-Development continuum, capability mix, spectrum of military utility and the importance of force maintenance were all highlighted by the Rwanda deployment? Implications for future humanitarian operations include a co-operative approach to pre-deployment training with the Non-Governmental Organisation (NGO) community. This will help to promote understanding between the arms of the humanitarian effort and will exploit the strengths of both sides. Equally, the military medical service have to be fully aware of mission definition and its centrality to planning, execution and audit of performance.

\section{Introduction}

In April 1994 the simmering political tensions in Rwanda finally erupted in the assassination of the president and the resultant genocide. There followed a 3 month civil war and a refugee exodus which has embarrassed the neighbouring countries of Tanzania, Burundi and principally Zaire ever since. At the conclusion of the conflict the population within Rwanda had declined from approximately 8.2 million to 4.4 million. In addition, the infrastructure of the country had suffered serious damage with its economy severely dislocated The refugees in Zaire underwent further tribulations with malnutrition and cholera affecting many in the hastily erected refugee camps particularly around Goma. It was at this stage, 3 weeks after the conclusion of the civil war, in July 1994, that the decision was taken to deploy a BRITCON as part of UNAMIR. The deployment was entitled Operation GABRIEL. .

Rwanda is in African terms a small country at the end of one of the horns of the Great Rift Valley (Fig 1). Its size is comparable to that of Wales, 180 kilometres east-west by 150 north-south. Its elevation gradually rises from the east to the west and as it does so the country is conveniently divided into 3 geographical zones (1). In the east the terrain is flat and has many water courses and lakes all of which lie at about 3,000 feet. The middle third includes the capital city, Kigali, and lies at 4,500 feet. It is characterised by rolling hills and larger, swifter flowing rivers. The western third possesses the high ground which varies from 14,000 feet in the northwest to 10,000 feet in the southwest and divides the country by a high ridge line. Within the south western comer lies a dense secondary jungle passable only by means of the road running to the border town of Cyangugu. This road was typical of the country in being in excellent condition. Unfortunately, many of the roads to smaller villages were dirt tracks with all the attendant difficulties in negotiating them especially during the wet season. The hilly nature of Rwanda is reflected in its title of "the Land of a Thousand Hills".

Rwanda lies at the watershed of the Nile and Zaire rived basins. It has tropical rain forest in much of the higher and wetter altitudes in the west, whilst the vegetation becomes progressively thinner and sparser in the south and eastras the climate becomes drier. The country lies one dege south of the Equator but the altitude keeps the aver@ge annual temperature to 19 degrees Celsius. The aver\$g rainfall is 85 millimetres per month but witho comparatively dry periods and 2 wet seasons every yean Before the war, malnutrition was virtually unknown sioges every available piece of land was used for cultivatione Cash crops were tea and coffee on which the courifry relied for foreign capital. The war disrupted bot subsistence farming and the plantation work with the inevitable degradation in food reserves and governmenta? finances.

The health threat assessment in Rwanda highlighted number of significant diseases. The main problem was likely to be enteric illness, dysenteries of all natures and cholera, but falciparum malaria also posed a problem Other diseases which required some attention include hepatitis A, rabies, HIV ( $30 \%$ of the population and $90 \%$ 爱 of the prostitutes were assessed as HIV+), meningitis an a variety of haemorrhagic fevers. Vaccination agains polio, tetanus, hepatitis A and meningitis and hepatitis boosters for medical personnel were given an $\stackrel{\Phi}{\Phi}$. mefloquine was used as a weekly anti-malarial.

The politics of Rwanda were complex but neede understanding prior to deployment. The countro comprised 3 ethnic groups; Pygmies (1\%), Tutsis (14\% and Hutus $(85 \%)$. Although these were described as ethnio and tribal groups, the reality was a little different. The tribal differences had been overlain by politica $\$$ allegiances and beliefs. Thus the moderate Hutu hatg suffered along with the Tutsis in the genocide. Originall the Hutu had formed the native indigent people. Some authorities believe that the Tutsis, who were taller and 
AS AT 05 AUG 94

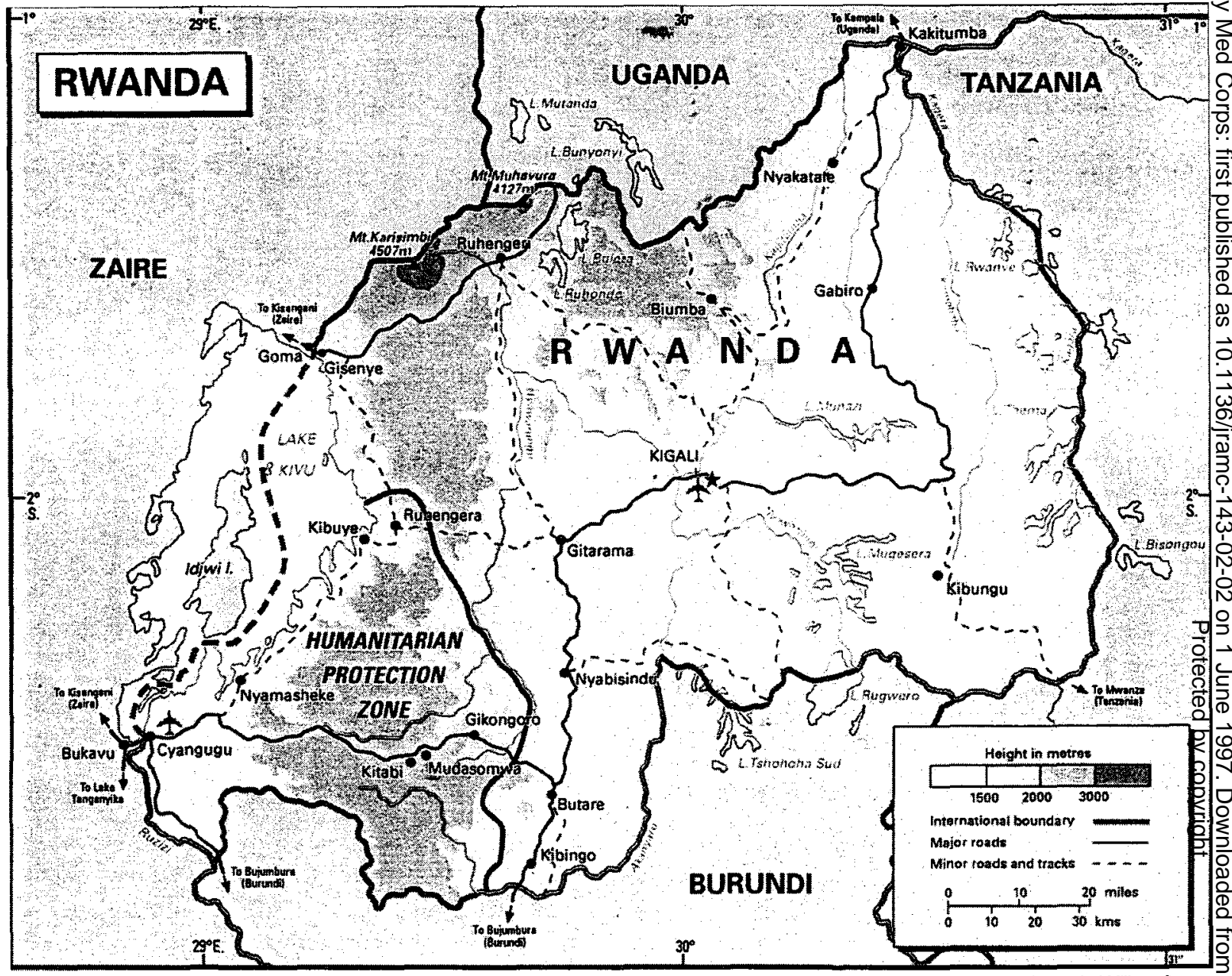

General Staff Map Section, GSGS 12080 (CAD), Edition 3 GSGS, August 1994 216/95 OP 13/2/95

Boundry representation is not necessarily authoritative.
Produced under the direction of Director General of Military Survey.

Ministry of Defence, United Kingdom 1995 .
(C) Crown Copyrighto

Fig 1.

more Ethiopian in appearance than the Hutu, had arrived in the country in the 1500 s having come down from the area of the Horn of Africa (2). Whatever the mechanism, the Tutsis soon acquired power and became the land holding and warrior class, whilst the Hutu formed the majority peasant class. In the late 1890 s the country was occupied as a colonial possession by Germany. The mandate passed to Belgium at the conclusion of World War One. Eventually, independence was granted in 1962. However, during the move towards independence, the Tutsis rose against the empowerment of the Hutu as the majority party in the new democracy. Thus started 30 years of intermittent and often bitter fighting. As a consequence of the conflict, the Tutsi were gradually driven from their traditional strongholds in the east of the country into exile in Uganda and into the northern and 
into Rwanda. Additionally, the French Army had set up a Humanitarian Protection Zone (HPZ) in the south west of Rwanda. This operation (Operation Turquoise) had been stimulated by a concern that the 1.5 million refugees living in the HPZ should be maintained in that area rather than move into Bukavu. Should such a population movement occur, it would overwhelm the ability of the humanitarian community to cope and a second tragedy similar to Goma would ensue at the southern end of Lake Kivu. This operation was greatly resented by the BBGNU and the Rwandan Patriotic Army (RPA) who harboured severe misgivings and suspicions of French intentions However, the integrity of the HPZ was respected by the victorious RPA who made no attempt to enter the zone and so allowed the French to stabilise the situation in the south eastern corner of Rwanda. This was the situation into which BRITCON was deployed.

\section{Operations in Rwanda}

The contingent sent to UNAMIR was largely drawn from 5 Airborne Brigade and specifically the Logistic Battalion (including equipment support), 9 Parachute Engineer Squadron and 23 Parachute Field Ambulance. Other elements, such as additional signals and environmental health teams, were grouped to BRITCON prior to deployment. A small infantry element of platoon strength was also included in the force. Hence, the flavour of BRITCON was one of combat support and combat service support rather than traditional combat arm and comprised 550 officers and soldiers. Within UNAMIR, contingents from various African states were joined by a substantial Canadian and Australian presence. The latter included a field hospital to be sited in Kigali and whose primary task was to be the support of UN forces.

The assumption prior to deployment of BRITCON was that humanitarian relief would form a significant part of the operation. On this understanding, it was decided to provide medical care for the refugee population using the recommended scaling as laid down by the World Health Organisation (WHO). These recommendations have been formalised into WHO packs which are designed to treat a population of 10,000 for 3 months. A total of 2 such packs was taken initially. Not only did this pack reflect the wide experience of the WHO and NGOs in refugee care, it also had the effect of harmonising treatment protocols, since the pack was built upon just such an approach.

Upon arrival in Rwanda, it quickly became clear that the infrastructure had been severely damaged by the war and that a considerable rebuilding programme would be required. This was outside of the competence of the military and needed a formal development policy to implement. Nevertheless, there were elements of the infrastructure which were identified as being key and even critical paths for the delivery of humanitarian assistance by the wider humanitarian community. One such task was the rebuilding of bridges and roads to enable food aid to be delivered.
In recognition of the need for strategic planning, COMBRITCON located his headquarters close to those of UNAMIR and the seat of government in Kigali. This $\frac{\widehat{\Phi}}{\mathcal{D}}$ became the strategic centre of the operations. Deployed away from this point was an engineering component in the $O$ north of the country and a composite group based on 23 응 Parachute Field Ambulance (23 Para Fd Amb Gp) which at first deployed up to the northwest of Rwanda.

The initial deployment of 23 Para Fd Amb Gp was predicated on a need to entice the 1.5 million refugees $\frac{\bar{F}}{\bar{m}}$ living around Goma in Zaire, back into Rwanda. In order $\frac{\infty}{\vec{D}}$ to achieve this, the abandoned hospital at Ruhengeri in the $\mathbb{\mathscr { D }}$ northwest was occupied by the group and put back into \& action. In addition, power and water supplies were $\vec{\circ}$ repaired and returned to the town and its surrounding areas. Clinical services were provided in the hospital $\vec{\omega}$ which quickly became a busy facility. The capability was further enhanced by the establishment of a food distribution point within the hospital grounds. This latter facility was provided by an NGO and became the model $\vec{A}$ for all subsequent working relationships with other aid agencies.

After 10 days operation in Ruhengeri hospital, it became clear that the French Army were planning to leave 0 the HPZ in the south west. This was a cause of concers since their presence had led to the stabilisation of the sector. Their withdrawal might well precipitate a furthe्षi exodus of the 1.5 million refugees who were then living if the HPZ and had come to rely upon the reassurance of the 8 French presence. Consequently, it was decided that 28 . Para Fd Amb Gp should be part of a re-deployment UNAMIR assets into the HPZ. The intention was continue to reassure the Hutu refugees in the sector and so prevent another flight from the country into Zaire.

This time the intention was clearly different from the Ruhengeri deployment. Instead of trying to entice a population back into Rwanda, the purpose was to create confidence so that they would stay. As there were approximately 1.5 million refugees living in 14 different camps, it clearly, required a concept of operations built upon an obvious physical presence and easily recognisable capability. Hence, it was decided that 23 Para Fd Amb Gp should occupy a site distant from the refugee camps and that travel to and from the camps on a daily basis would form part of the physical presence and reassurance strategy. By this approach it was intended that confidence would be established among the refugee population.

The usual priorities of clean water, route maintenance, $o$ preventive medicine measures and information gathering were completed or started before a clinical programme was initiated. Then clinics were set up in both refugee camps and villages. This latter was deemed necessary o because of experience in Goma. In that area, the provision $N$ of aid to the refugees had created resentment amongst the N local population. Subsequently, the uneasy tensions had been exacerbated by communal violence. This clearly had 
to be avoided if the refugees were to be persuaded to remain in the HPZ. Hence, the village improvement programme was initiated.

Liaison and agreement with the NGO community was accomplished by a regular set of committee meetings. These were chaired by the United Nations Rwanda Emergency Organisation (UNREO) and included all the UN agencies and NGOs operating in the sector. A similar committee operated at national level. As the HPZ stabilised, the BBGNU appointed its own nominee to chair the regional committee just as the Minister of Health did on the national forum. These developments were key to co-ordinating and planning the humanitarian effort.

Once the situation came under control and it was clear that the refugees were not about to flee the country, it became possible for 23 Para Fd Amb Gp to commence other aid projects. The hydro-electric plant supplying the town and region of Gikongoro was repaired. Further bridge and road repair was completed. Medically, there were a number of joint projects, notably with MERLIN and Medicin Sans Frontieres, to provide additional care initiatives. A total of 95,453 vaccinations against meningitis and measles were delivered to children in the camps. In the same vein, antenatal clinics were set up in the camps. Similarly, nutritional surveys were undertaken to monitor and audit the food aid programme.

On completion of the tour, the task of providing care in the camps was able to be handed over to the NGO community. This was successfully achieved by liaison and negotiation. The techniques of a relief in place were used with conspicuous success. During the 3 months in which BRITCON had been declared operational, a total of 132,605 treatments had been given, 5.4 million litres of clean water produced, 98 culverts repaired, 12 bridges built, 3,308 mines and unexploded ordnance made safe, 467 vehicles repaired and 5 orphanages refurbished. Table 1 gives the breakdown of the medical statistics. The situation in the HPZ had been stabilised and the mission had been accomplished.

Table 1.

Treatments carried out in Operation GABRIEL.

\begin{tabular}{lll}
\hline WHO Classification & $\begin{array}{l}\text { Number of } \\
\text { Treatments }\end{array}$ & Percentage \\
\hline Diarrhoea & 33,735 & 25.44 \\
Diarrhoea with blood & 13,320 & 10.04 \\
Meningitis & 63 & 0.05 \\
Measles & 82 & 0.06 \\
Respiratory Infection & 5,878 & 4.44 \\
Malaria & 20,159 & 15.21 \\
Others & 59,179 & 44.62 \\
Surgery & 189 & 0.14 \\
\hline Total & 132,605 & \\
\hline
\end{tabular}

\section{Issue A rising from the Operation}

The deployment of BRITCON to Rwanda in 1994 was one of the largest humanitarian operations mounted by the UK Armed Forces in recent times. Only Operation HAVEN, aid to the Kurdish refugees in Northern Iraq, matched it in terms of scale and quick response. Accordingly, many issues were highlighted by the deployment and have been explored subsequently. Some of the larger issues and concepts are examined below.

\section{Principles of Humanitarian Relief.}

On the basis of experience in humanitarian support in both Kurdistan and the Former Republic of Yugoslavia, an interim doctrine on Wider Peacekeeping was produced by the Inspector General of Doctrine and Training (4). The experience gained in Rwanda substantially confirmed the value of the interim doctrine.

Liaison and Co-ordination with NGOs and local community leaders was vital This was a sizeable task which demanded a full time civil liaison officer to be created in order to accomplish it. On the initial move into the HPZ, a total of 14 NGOs were operating in the sector. At the completion of the tour, this number had mushroomed to 118 . The NGOs varied from the experienced and professional organisations like the 0 International Committee of the Red Cross (ICRC) and Medicin Sans Frontieres who possessed both wide $\stackrel{\mathbb{D}}{\circ}$ expertise and more than one capability, to small single issue NGOs comprising a few determined and committed individuals. Hence, both the number and the variety of NGOs rendered the task of liaison and co-ordination complex. Compounding this difficulty was the reluctances on behalf of many NGOs to accept the role of the military in humanitarian relief.

It took time, patience and detailed discussion to establish the appropriate level of co-ordination between all agencies. Based on this experience, it is likely that the lead in creating the correct climate of trust and cooperation between uniformed and civilian humanitarian players will lie with the military. Suspicions and misgivings will need to be resolved at the local level.

Security is a crucial element for a successful humanitarian relief operation. A civilian population needs to feel safe and no longer threatened before they can begin to avail themselves of the assistance offered. The military have a leading role to play in this by creating the appropriate climate of safety and security. In addition, the operations of the NGOs also need to be protected from interference by warring parties. This may mean a more overt military posture being adopted.

Timeliness is clearly of relevance. Disasters requiring humanitarian assistance arise because of an overwhelming short notice human need which swamps the capacity of the local infrastructure. By definition, the need is large and immediate. Hence, delay in deployment will mean avoidable human loss and distress. During the Rwandan deployment, BRITCON managed to have its 
lead elements in the country within 10 days and all its major functional components within 3 weeks. This was a speed of response which was exceptionally rapid and was only constrained by the availability of airlift. In this case, nearly all the aircraft were acquired from the United States Air Force.

Priorities need early recognition and resourcing. The identification of needs is a prerequisite for correct force structure and composition. It will also be essential to the formulation of the mission statement. In the case of Rwanda, there was confusion before arrival in the country, between the stated priorities by the Commander UNAMIR and the United Nations Headquarters in New York. In recognition of this disparity, BRITCON was so constructed that both competing sets of priorities could be met but with emphasis being placed on the Commander's perceptions.

Unity of Effort is clearly desirable in a situation of immediate human need. By such an approach, maximal effectiveness of humanitarian effort can be achieved. However, with a profusion of different agencies involved it is unlikely to be possible to achieve complete unity by complete agreement. It may be possible in the early stage of an emergency response, but such consensus is likely to break down as the acute phase of the crisis passes. Nevertheless, it is worthwhile trying to obtain unity of effort since consensus is valuable even if complete agreement between all humanitarian agencies is impossible.

Information gathering is another requirement in humanitarian relief. Whilst it is not stated as one of the principles in the interim doctrine, without an effective information gathering system it is difficult to see how a successful operation could be mounted. Necessary information includes epidemiological data. This is notoriously difficult to obtain and frequently requires the setting up of a data capture and retrieval system (5). Such information is vital for purposes of medical audit and prioritisation. However, other types of information will also be of importance. In the case of Rwanda, a complete reconnaissance plan for the HPZ was required since no useful global information was available from $\mathrm{UN}$ or NGO sources about the locations, sizes, access and humanitarian support being provided to the camps in the sector. This information gathering took the entire assets of 23 Para Fd Amb Gp, less one medical section, a complete week to accomplish. At the end of that time, a matrix of data outlining all the details about the camps and the activities of NGOs within them had been created. This allowed priorities to be identified and duplication of effort to be avoided. Careful presentation of the case for coordination needed to be ensured in order to avoid antagonism with the NGO community. It also has to be borne in mind that any suggestion of covert intelligence gathering will be both resented and will also be ethically difficult to square with the nature of a humanitarian relief operation.

\section{Mission Definition.}

A humanitarian operation needs clarity of misston statement no less than a more conventional militiry manoeuvre. Indeed, in the chaos, confusion and complexity of refugee flight and mass populacon movement, a clear statement and understanding of कुhe mission becomes crucial. Without it, not only can mission analysis, estimate and planning be completed, the very cohesion of the humanitarian force canobe gradually undermined by inevitable drift and delay in प्ऱe face of an overwhelming human need. For this reashn, medical commanders in this sort of situation must receive a clear mission and have the necessary skills to compdete the estimate and planning process.

In Rwanda, 2 separate missions were given to 23 P Fd Amb Gp. The first came as a result of the initjal meeting on arrival in the country between ghe commanding officer and the UNAMIR commander. The briefing given to CO 23 Para Fd Amb Gp made clear 角at the intention was to persuade refugees who had fled'to Goma, to return to Rwanda. As a result a missionn statement was formulated by CO 23 Para Fd Amb Gp \&̂d briefed back for approval and authorization. The agréd mission statement gave direction as follows:

23 Para Fd Amb Gp is to provide humanitarpa assistance in the northwest of $R$ wanda in orde? $\vec{t}$ encourage refugees to return to tbe country figm

Zaire. ¿

Analysis of this mission led to a concept of ope醉的s based upon a need to entice people back. Henco, The hospital and then town of Ruhengeri were provides with facilities which had been damaged during the conffe? It was an attempt to set up a "honey-pot" to attrae fhe population back.

Equally, when a new mission was issued on withdrawal of the French from the HPZ, a similar process of briefing back was undertaken. This time the staten read as follows:

23 Para Fd Amb Gp is to provide humanitariag assistance in the southwest of $R$ wanda in order to encourage the refugee population to stay in that part of the country.

Mission analysis again led to a concept of operating which was based upon the need to reassure the refugee population and build confidence amongst them. In case, the techniques adopted included high visibility and an obvious presence on the ground.

Possession of a clear mission statement also proviles the benchmark against which performance can Zbe monitored. In essence, it is the measure for succesefful audit. It will also set limits and highlight constraints and freedoms whilst defining the capabilities required andqhe relative importance of each. As such, it can be seen clarity of mission becomes absolutely essential to. Phe delivery of humanitarian assistance by the military. 


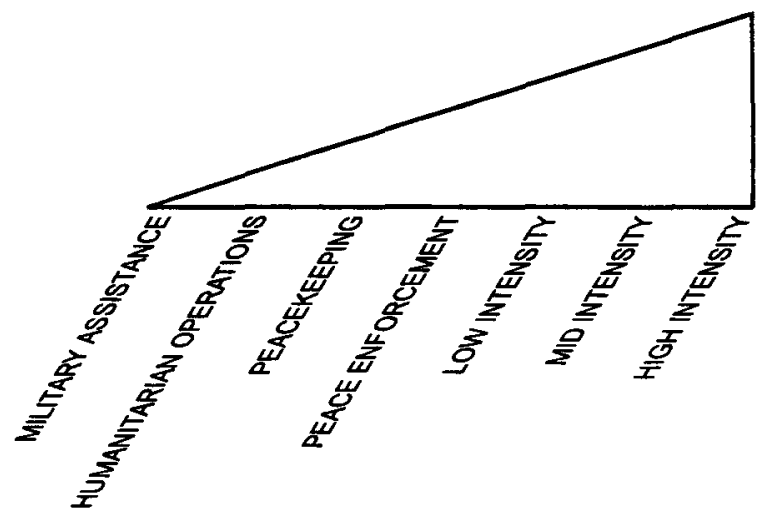

Fig 2. Spectrum of Military Utility.

\section{Spectrum of Military Utility.}

Any use of the military will bring with it political consequences. This point is clear and well understood when applied to high intensity conflict. Many are familiar with the classical statement by Clausewitz, "War is the continuation of politics by the admixture of other means" (6). This is a fundamental truth. The application of military force must have political point and, equally, possesses political significance and intent. The same reasoning applies to the employment of the military on operations lower down the spectrum of military utility. Figure 2 is a schematic representation of the spectrum of military utility.

When uniformed personnel are deployed on humanitarian operations they carry with them the legitimacy of the authority which commands and supplies them on operations. This might be either national or United Nations. In either case, they are operating with the tacit support of their national government and ultimately remain accountable for their actions to their chain of command. This accountability has advantages and disadvantages, particularly for a country like the UK with an active and recent colonial history. Any commitment of the military is likely to be viewed as some sort of statement of political intent and interest.

Additionally, the actual work of humanitarian assistance may itself possess political significance. Thus, food delivery to a needy people means continued life for them. It also may become the coinage for political power, patronage and influence. One of the problems of food distribution in Rwanda and Zaire centred around this very point. In order to organise food distribution in the most effective and efficient manner to the camps, it is normal procedure to use the existing social structure and leadership. By this means the policing and delivery of the food to the point of consumption can be assured and monitored. However, in Rwanda this existing social camp structure continued to empower the Hutu leaders who were implicated in the genocide of the war. The leaders in the camps tended to be the community leaders of the prewar Hutu society and these were the very people accused of organising the campaign of genocide. This situation required careful policing to ensure that no abuses of the political power which responsibility for food distribution $\mathbb{D}$ gave, were actually perpetrated. Any easy acceptance of such abuse would have been interpreted as support by 230 Para Fd Amb Gp for one faction rather than another.

It is an inescapable fact that the deployment of the military on humanitarian operations carries with it the risk $\stackrel{\vec{s}}{s}$ of escalation up the spectrum to more overtly militaryo activities. The possession of weapons with the potentialo for applying lethal force clearly emphasises this point. In $\frac{\bar{\rho}}{\frac{1}{6}}$

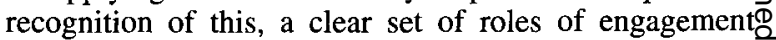
(ROE) are required. Such clarity of guidance is essential.» Yet this ability to respond to situations with force is one of the advantages which a military force can bring to a. situation. Whilst many medical units fight shy of the $\vec{\omega}$ weapon handling dimension, there are situations in whicho the carriage and readiness to use them may conferō considerable advantage. Any decision regarding arms 3

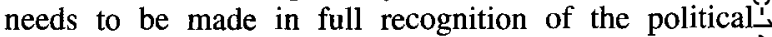
context and consequences of the policy. Clausewitz' tenet $\vec{\omega}$ needs to be borne in mind.

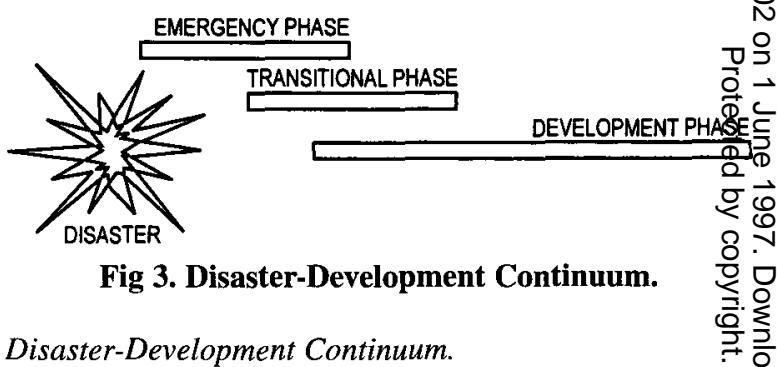

A useful construct, as seen in Figure 3, through which to examine the significance of emergency humanitarian® relief is provided by the Disaster-Development Continuum. This approach sees a gradual progression了 from the immediate impact of a disaster, through the provision of emergency relief and a transitional stage to the different and longer lasting initiatives of the development programme. The role of the military is properly restricted to the emergency relief stage for $2 \frac{0}{2}$ reasons; a quick return to the operational order of battle is $\bar{\varnothing}$ generally desirable, and the military are not equipped or suited to undertake a long term development project. Such? a venture requires a substantial commitment of resources 3. into rebuilding a country's infrastructure. This is besto carried out by a joint effort comprising relevant NGOs, 3 UN agencies, indigent government and multiparty aido agreements.

However, in a situation like that faced by Rwanda ino 1994, an inappropriate response at the emergency relief stage can compromise the subsequent developmento programme. The emergency intervention must be $\mathrm{O}$ culturally and economically appropriate and relevant. Initiatives which require long term continuation ando sophisticated technology may be insupportable. Worseo 
still, they may affect and promote expectations amongst the population which are not sustainable and hence breed resentment and opposition to the development plans. Instances of this were seen in Rwanda on Operation GABRIEL in 1994. One such example concerned the treatment of TB. The disease abounded in the post-war society of Rwanda. However, the therapeutic regime required treatment for 7 months. Since the operational tour of BRITCON was restricted to 3 months, a decision was taken not to treat TB. It was a decision which many found difficult to accept. However, the impossibility of continuation of treatment after 3 months made the decision sensible. Another example was seen in the HPZ when a 4 year old girl presented with profound osteomyelitis of the left tibia from the earlier application of external fixation. This apparatus had been successfully applied by an aid organisation 3 months before presentation. No review had been conducted and no equipment was available to remove the fixator. Consequently, there was no alternative except below knee amputation. If the traditional and more conservative Rwandan technique of splinting using wooden poles and traction using sand filled buckets had been used, this unhappy outcome could have been avoided. Adherence to the contents and protocols contained within the WHO packs will also help to avoid inappropriate treatment.

A clear understanding of the Disaster-Development Continuum will provide a useful way of viewing the role of military emergency humanitarian relief. Whilst the construct has limitations and is the subject of much debate amongst the humanitarian community, it remains useful as an indication of the relationship between the different stages of a society's recovery from disaster.

\section{Capability Mix.}

Following on from the continuum is the requirement to employ a suitable capability mix in emergency humanitarian interventions. This mix should initially settle the balance between the separate capabilities possessed by different capbadges. Thus, civil engineering and logistic capability will frequently be priorities as will combat arm presence for security. Equally, medical assets will form a powerful weapon in the humanitarian armamentarium.

The mix of medical skills will depend upon the mission and the need assessment. For the operation in Rwanda, an early decision was made that preventive medical expertise (primarily environmental health teams) and a level of clinical treatment based upon the generalist, was likely t,o prove most suitable. Thus, medical officers were either General Practitioners or General Duty Medical Officers with specialist capability only being supplied by a Field Surgical Team and a psychiatrist. No other specialist was taken in the skill mix. This approach ensured that overtreatment was unlikely and the logistic support required was minimal. In addition, it guaranteed that the response could be mounted quickly and that it remained flexible to changing tactical and medical circumstances on the

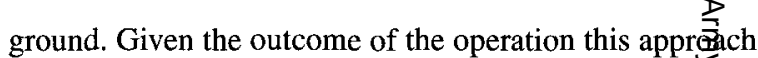
was shown to be correct. The one element which was missed was that of midwifery. Few of the combat medical technicians felt confident when faced by pregexant casualties and there were too few medical officers qith postgraduate obstetric experience.

It proved appropriate to deploy a Role 2 medical uniton this task because of the nature of the ground, tactical situation and mission A hospital facility would not Eave added anything substantial to the ability to meet产he mission and would have imposed considerable log tic and security complications. Whilst hospitals ha\& a superficial attraction as an easy response to emergo humanitarian operations, the disadvantages outweigh-the advantages in the austere setting and immediate needs of a situation like Rwanda in 1994. Instead, clindeal capabilities possessed by a hospital may be use Rlly regrouped to a Role 2 unit and deployed on red scales. The temptation to over-treat must, howeve resisted.

\section{Force Maintenance.}

It remains a prime responsibility of both a commatroler and the medical services to conserve a force's strengt 5 by the prevention of disease and the maintenance of $\mathrm{He}$ alth. The rapid return to duty of those who fall sick fre are injured is also a priority. Thus, at all stages \&f operation in Rwanda priority was given to ensuringecean water, safe sanitation, vector control and prophylaxis before humanitarian activities were sparted. Naturally, the engineer and environmental healthoeams were central to this function. The success of programme can be judged by the low rate of dise non-battle injury casualties which were maintained gt a daily average of $1.09 \%$ for the tour with a 3 day incre at week 5. This coincided with the onset of the rains 3 and rose to a rate of $3.9 \%$. It subsided after 3 days.

Psychological support for operations has recently been highlighted. For this deployment, an initial assessme of psychological stressors and groups at especial risk

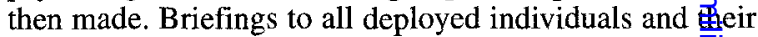
families were then given and after deployment the uiual critical incident debriefing facility was made availe. Prior to return to UK, discussion groups were hels in Rwanda and a short pamphlet outlining pos sible individual reactions, was issued to all families. On requrn to UK follow-up of all individuals was undertłken through discussion groups and questionnaires. $8 \mathrm{O}$ immediate arrival in UK the entire force worked norna for 3 weeks before departing on leave. Using ghis comprehensive approach, a high quality psychological support service was run.

The role of the Field Surgical Team (FST) is a matta of careful planning. Clearly, there is a requirement for the surgical support of own forces. At the same time, sursscal expertise will always be at a premium in humanitan crises. Therefore, a balance needs to be struck betweethe 2 roles. They should not be intermixed since this wilksead 
to confusion and mission creep. All aspects of surgical care will need to de addressed. This includes postoperative care and rehabilitation. These aspects were extremely difficult to resource on Operation GABRIEL and required assets from the rest of 23 Para Fd Amb Gp to undertake the care appropriately.

It is clear that on operations such as Rwanda 1994, 2 sets of treatment protocols and equipment must be maintained. In this operation, a set of equipment based on normal medical scalings was used for treatment of own and other UN forces $A$ different set of equipment and schedules were used to deliver medical care to the refugees. The 2 scales were different and were not interchangeable. This is likely to be a continuing requirement for similar deployments in the future. It is the obvious way of reconciling the need to avoid overtreatment of a refugee population, with an appropriate and high quality western style medical care to own troops. It is a necessary but difficult balance to strike.

\section{Conclusions}

The ending of the Cold War has seen the stability of the old superpower antagonism replaced by a growing number of regional inter - and intra-state conflicts. Many of these have involved destruction on a massive scale and a few have seen genocide perpetrated. All of them have seen calls for UN involvement and hence the commitment of military forces (7). Operation GABRIEL as part of UNAMIR in 1994 was just such a deployment.

The humanitarian needs seen in Croatia, Bosnia, Cambodia, Somalia and Rwanda have all witnessed the requirement for the military and NGO communities to work together (8). The experience has not necessarily been easy for either side and many lessons have been learnt. However, the Rwanda deployment illustrated the advantages of joint action between all humanitarian players. Indeed, it graphically demonstrated the synergy that can derive from a facilitating military presence and a committed and well resourced NGO effort.

It seems likely that similar deployments will occur in the future. In order to ensure the maximum effectiveness in these short notice deployments, it would be helpful if a common approach to problem solving could be developed. It is probably too much to expect interoperability between military and civilian agencies. However, a mutual understanding of strengths and weaknesses would certainly be advantageous. This would allow realistic goal setting to be achieved and would greatly assist a combined humanitarian effort. Training for deployment would certainly benefit from a common approach and in this respect the military is well situated to offer advice and expertise.

Preparation for a military force about to deploy on humanitarian operations should also include a package for㐫 working with NGOs. Existing links with the NGO community, many of which have been forged and tested ino the field, should be fostered and incorporated in suchos? training. The bulk of experience in humanitarian relief is $\Rightarrow$ held by the full-time professional staff in the NGO community. This is a valuable resource which should be approached for advice and training. In return, the strengths of the military should be used to assist the NGOO effort in preparation for deployment. The co-operative effort, which is enshrined in the doctrinal approach to humanitarian relief, could be cemented even beforedeployment.

Training for these sort of operations is now being $\vec{\omega}$ introduced by the military. This is a belated recognitions that many future deployments are likely to involveg humanitarian relief and also that this is one point on the spectrum of military utility. For the medical services this challenge is of a higher order than for other cap badges. This is a result of the different treatments, equipments and even ethical approach needed for refugee relief. No othero component of the Armed Forces faces such a fundamentalo change in basic function in the field. Therefore, in order meet the challenge it is essential that training is institutice in peacetime and that it is made relevant to the entifes spectrum of military utility rather than the traditiom ${ }^{\infty}$ fixation on high intensity conflict. Using this approag $\vec{\theta}$ the military medical services can not only play a full rgein the actual delivery of humanitarian relief, they can a facilitate the efforts of the civilian sector.

\section{REFERENCES}

1. WALleR D. Rwanda Which Way Now? Oxford:这 Oxfam, 1993, 3-4.

2. KEANE F. Season of Blood A Rwandan Journey Harmondsworth: Penguin, 1995; 11-20.

3. VASSEL-ADAMS G. Rwanda - An Agenda for International Action. Oxford: Oxfam, 1994; 28-34.

4. HMSO. Wider Peacekeeping. London, 1994; 3: 16-3 18.

5. JOK J M. Information Exchange in the Disaster Zone: Interaction Between Aid Workers and Recipients in South Sudan. Disasters 1996; 20: 206-215.

6. Howard M, Paret P. Carl von Clausewitz - On Waró Princeton: Princeton University Press, 1976, 87.

7. Minear L, Weiss TG. Mercy Under Fire. Boulder:̊̊ Westview, 1995; 27-30.

8. SтосктоN N. Defensive Development? Re-examining the Role of the Military in Complex Politicab Emergencies. Disasters 1996; 20: 144-148. (n) 